\title{
Advances of Nanofluids in Solar Collectors - A Review of Numerical Studies
}

\author{
Younes Menni $^{1 *}$, Ali J. Chamkha ${ }^{2}$, Giulio Lorenzini ${ }^{3}$, Noureddine Kaid ${ }^{4,5}$, Houari Ameur ${ }^{5}$, Mohammed Bensafi ${ }^{4}$ \\ ${ }^{1}$ Unit of Research on Materials and Renewable Energies, Department of Physics, Faculty of Sciences, Abou Bekr Belkaid \\ University, B.P. 119, 13000, Tlemcen, Algeria \\ ${ }^{2}$ Mechanical Engineering Department, Prince Sultan Endowment for Energy and Environment, Prince Mohammad Bin Fahd \\ University, Al-Khobar 31952, Saudi Arabia \\ ${ }^{3}$ Department of Engineering and Architecture, University of Parma, Parco Area delle Scienze, 181/A, Parma 43124, Italy \\ ${ }^{4}$ Laboratory of Energy in Arid Areas (ENERGARID), University of Bechar, B.P. 417, 08000, Bechar, Algeria \\ ${ }^{5}$ Department of Technology, University Center Salhi Ahmed of Naâma (Ctr Univ Naâma), B.P. 66, 45000, Naâma, Algeria
}

Corresponding Author Email: menniyounes.cfd@gmail.com

https://doi.org/10.18280/mmep.060313

Received: 6 April 2019

Accepted: 22 June 2019

\section{Keywords:}

nanofluid, base fluid, heat transfer, fluid

flow, solar collector, numerical simulation

\begin{abstract}
This paper presents a detailed review of the numerical studies carried out by various researchers in order to obtain enhanced heat transfer in free, forced, and mixed convection, under laminar, transition, and turbulent flow regimes, by using nanofluids in different solar collector geometries. Recently, nanofluids have been increasingly used in various solar collector configurations. Nano-sized metallic or non-metallic particles such as $\mathrm{Cu}, \mathrm{Au}$, $\mathrm{Al}_{2} \mathrm{O}_{3}, \mathrm{SiO}_{2}, \mathrm{TiO}_{2}, \mathrm{CuO}$, etc, were used in the heat transfer fluid for various solid volume fractions. The average size of the particles was less than $100 \mathrm{~nm}$. The higher conductivity of nanoparticles even at low particle concentration results in higher thermal conductivity of the base fluid and improves the thermal characteristics of the system. Nanoparticle size, type and shape are important factors for the thermal conductivity enhancement of the nanofluid with nanoparticles.
\end{abstract}

\section{INTRODUCTION}

The low thermal conductivity of conventional heat transfer fluids, common water, oil, and ethylene glycol, has restricted the improvement of thermal systems performance. Fluids containing nano-sized solid particles offer a possible solution to conquer this problem. The nanofluid has greater effective thermal conductivity than a pure base fluid. Nanofluids, a name conceived by Choi [1], are fluids consisting of solid nanoparticles with size less than $100 \mathrm{~nm}$ suspended with a specified solid volume fraction.

Nanofluids can be used to improve thermal management systems in many engineering applications such as storage of radioactive nuclear waste, solar collectors, transpiration cooling, performance of cold storage, separation processes in chemical industries, thermal insulation of buildings, filtration, space technology, transport processes in aquifers, nuclear reactor cooling system, groundwater pollution, underground nuclear wastes disposal, geothermal extraction, and fiber insulation, etc. Due to the encouraged enhanced properties associated with nanofluids properties, huge works have been published since about two decades ago [2-10]. Different concepts have been proposed to explain this enhancement in thermal performance, which results to be higher with respect to that of classical mixtures.

This paper presents a detailed review of the numerical and experimental studies carried out by various researchers in order to obtain enhanced heat transfer in free, forced, and mixed convection, under laminar, transition, and turbulent flow regimes, by using nanofluids in different solar collector geometries.

\section{NANOFLUID FLOWS}

These new fluids have received a considerable attention and have been the subject of many investigations. Among them, Ajeel et al. [11] numerically performed heat transfer and flow characteristics of the symmetry semicircle-corrugated channel with $\left(\mathrm{SiO}_{2}\right)$-water nanofluid was over Reynolds number ranges of 10,000-30,000. The influence of geometrical parameters including height-to-width ratio and pitch-to-length ratio on the thermal and hydraulic characteristics were evaluated. A numerical simulation covering nanofluid with $\mathrm{SiO}_{2}$ volume fractions of $0-8.0 \%$ was carried out by employing the finite volume method for discretization of the governing equations. The outcomes revealed that the heightto-width ratio has greater influence on the promotion of heat transfer compared to the pitch-to-length ratio. At Reynolds number 30,000 , there was $13.59 \%$ increment in average Nusselt number due to a decrease of the pitch-to-length ratio from 0.175 to 0.075 , with an increment of about $78.84 \%$ due to an increase of the height-to-width ratio from 0.0 to 0.05 . The results indicated that the height-to-width ratio of 0.05 with a pitch-to-length ratio of 0.075 are the optimum parameters and have shown significant improvement in thermal performance factor. Furthermore, new correlations for Nusselt number and friction factor were developed and reported.

Ajeel et al. [12] numerically conducted the turbulent forced convective of four nanofluids types $\mathrm{Al}_{2} \mathrm{O}_{3}, \mathrm{CuO}, \mathrm{SiO}_{2}$, and $\mathrm{ZnO}$ flowing in trapezoidal-corrugated channels over Reynolds number in the range of $10,000 \leq \mathrm{Re} \leq 30,000$. Regarding the nanofluid, the impact of different values of nanoparticle volume fractions with ranges of $0-8 \%$ and 
nanoparticle diameters with ranges of 20-80 nm was discussed. The major conclusion of this numerical study was that the utilization of nanofluid in corrugated channels can be offered as an appropriate way to get best thermal performance, which can prompt design plan of heat exchangers and make it more compact.

Bezaatpour and Goharkhah [13] carried out a three dimensional numerical simulation to study the effect of porous media on the heat transfer and pressure drop of magnetite $\left(\mathrm{Fe}_{3} \mathrm{O}_{4}\right)$ /water) nanofluid flow in two conventional heat sinks; circular and rectangular channel heat sinks. The effects of different parameters such as nanofluid volume fraction and flow rate and channel porosity on the performance of the heat sinks were investigated. A maximum heat transfer enhancement of $13 \%$ and $14 \%$ was achieved by using nanofluid in clear rectangular and circular channel heat sinks, respectively. These values grow up to $450 \%$ and $547 \%$, respectively when the heat sinks are filled with the porous media. The heat transfer enhancement due to the insertion of the porous media was accompanied by very large pressure drop. The results indicated that the overall heat sink performance is improved at low flow rates and porosities and high concentrations of the nanofluid.

Dormohammadi et al. [14] investigated numerically the effect of the geometrical parameters and nanoparticles dispersing into base fluid on the heat transfer characteristics and entropy generation inside a sinusoidal wavy-wall channel. A two-dimensional CFD simulation was developed for modeling steady, incompressible and laminar flow of $\mathrm{Cu}$ water nanofluid flow within the channel. The effects of geometrical and flow parameters, including nanoparticles volume fraction, Richardson number, wave amplitude ratio and wave length ratio, were investigated.

Joseph and Sajith [15] focused on the study of heat transfer performance of polystyrene encapsulated phase change material (nanoPCM) based nanofluid. The nanoPCM was synthesized by miniemulsion polymerization in which PCM core (n-octadecane) is encapsulated within polystyrene shell. The nanoPCM was characterized by Scanning Electron Microscope (SEM), Particle Size Analyser (PSA), Differential Scanning Calorimetry (DSC) and Fourier Transform Infrared (FTIR) spectroscopy. The PCM nanofluid was prepared by dispersing nanoPCM in deionized water and the thermophysical properties of the nanofluid were estimated. The optimum concentration of PCM nanofluid for maximum stability was fixed as $0.7 \% \mathrm{v} / \mathrm{v}$, based on zeta potential measurements. The heat transfer and pressure drop studies of PCM nanofluid were conducted in a square channel of $8 \mathrm{~mm}$ hydraulic diameter. The PCM nanofluid showed up to $37 \%$ improvement in heat transfer performance as compared to deionized water (DI water). The results revealed that heat flux and flow rate of PCM nanofluid plays a crucial role in heat transfer performance. A slight increase in pressure drop and the pumping power was observed for the PCM nanofluid as compared to deionized water, especially at higher mass flow rates due to the increase in the viscosity of PCM nanofluid.

Minakov et al. [16] carried out experimental study of forced turbulent convection of water-based nanofluids with nanoparticles of zirconium oxide $\left(\mathrm{ZrO}_{2}\right)$ in smooth tubes and channels with wall heat transfer enhancers. Nanopowders with average particle size of 44 and $105 \mathrm{~nm}$ were used in the experiments. The Reynolds number ranged from 3,000 to 8,000 . It was revealed that the increments in the heat transfer coefficient and the pressure drop when using nanofluids depend on the surface shape of the channel. It was shown that nanofluids allow reaching thermal-hydraulic efficiency comparable to that of the channels with artificial heat transfer enhancers.

Mohebbi et al. [17] carried out a lattice Boltzmann method to investigate the forced convection flow of the nanofluids in a channel with extended surfaces attached to its both walls on the effect of changing different parameters such as solid volume fraction, Re, obstacles' height, and spacing between them. The results indicated that the average Nusselt number increases when the nanofluid concentration increased from $0 \%$ to $5 \%$. Moreover, the effect of the nanofluid concentration on the increasing of heat transfer was more noticeable at higher values of the Reynolds number. It was concluded that the use of extended surfaces can enhance the rate of heat transfer for certain arrangements. They also showed that the nanofluid with $\mathrm{CuO}$ nanoparticles performed better enhancement on heat transfer compared $\mathrm{Al}_{2} \mathrm{O}_{3} /$ water and $\mathrm{TiO}_{2} /$ water nanofluids.

\section{HEAT AND NANOFLUID TRANSFER}

Among important contributions, Ameri and Eshaghi [18] focused on the evaluation and feasibility study of laminar $\mathrm{Fe}_{3} \mathrm{O}_{4}$ nanofluid flow in porous media with a constant magnetic field in a flat plate collector (FPC) which is known as the novel system in comparison to porous foam utilization in the FPC absorbing tubes tube with laminar water flow which is known as the Rival system. The simulation was performed for a various constant magnetic field, absorbing fluid mass flow rate and different nanoparticle weight fractions. The newly introduced feasibility indicator parameter (FIP) factor for the Novel system was higher than unity for 200 G constant magnetic field and $1 \%$ to $2 \%$ nanofluid weight fraction. The FIP value reaches the maximum values of 1.105 and 1.045 for $1 \%$ and $2 \% \mathrm{wt}$, for $200 \mathrm{G}$ constant magnetic field values and the Reynolds of 417.4, respectively.

Bazdidi-Tehrani et al. [19] numerically studied the turbulent forced convection of $\mathrm{TiO}_{2}$ /water nanofluid through a ribbed flat-plate solar collector. The scale-adaptive-simulation approach was employed to simulate the turbulent flow through the plain and ribbed ducts which are surrounded by solid flatplate. The efficiency of flat-plate solar collector increased with the nanoparticles volume fraction whilst an enhancement in the efficiency of the ribbed duct was approximately $10 \%$ higher than that of the plain duct. This enhancement varied for different nanofluids such that the $\mathrm{CuO}$ /water nanofluid provided a higher thermal efficiency than that of $\mathrm{TiO}_{2} /$ water.

Bellos and Tzivanidis [20] examined the utilization of nanofluids as working fluids of solar collectors which drive an absorption chiller operating with the $\mathrm{LiBr}-\mathrm{H}_{2} \mathrm{O}$ working pair. The selected solar collector was a flat plate collector and the examined nanofluid was created by dispersing $\mathrm{Cu}$ in water base fluid. The study was conducted with a numerical model developed in EES. This model was validated with experimental results from laboratory tests about the solar collector and from literature results about the absorption chiller. During the daily simulation of the system, the mean daily exergetic efficiency enhancement was found $3.99 \%$ while the system COP and the cooling production enhancement were found $0.84 \%$ enhanced. More specifically, the maximum cooling production was observed at the solar noon and it was $30.69 \mathrm{~kW}$ for the nanofluid case and $30.32 \mathrm{~kW}$ 
for the water case.

Edalatpour and Solano [21] numerically investigated the various parameters of heat transfer in a 30-degree inclined three-dimensional tube-on-sheet flat plate solar collector working under conjugated laminar mixed convection. The simulations were performed for water with different concentrations of $\mathrm{Al}_{2} \mathrm{O}_{3}$ nanoparticles. The results revealed that increasing the volume fraction of nanofluid at a fixed Reynolds number declines the outlet temperature whereas lowering the Reynolds number at a same volume fraction gives rise to higher outlet temperature. From heat transfer standpoint, it was observed that in a constant Reynolds number by increasing nanoparticle volume fraction, the Nusselt number falls while the heat transfer coefficient rises. In addition, rising the Reynolds number eventuated in friction factor reduction while the pressure drop augments. Moreover, from the obtained outcomes, it was figured out that generally using alumina/water nanofluid provides lower total entropy generation, in comparison with the water. Simulation data revealed that alteration in the heat flux does not have any sensible effects on the friction factor.

Faizal et al. [22] carried out an analysis to estimate the potential to design a smaller solar collector that can produce the same desired output temperature. Using numerical methods and data from literatures, efficiency, size reduction, cost and embodied energy savings were calculated for various nanofluids. From the study, it was estimated that $10,239 \mathrm{~kg}$, $8625 \mathrm{~kg}, 8857 \mathrm{~kg}$ and $8618 \mathrm{~kg}$ total weight for 1000 units of solar collectors can be saved for $\mathrm{CuO}, \mathrm{SiO}_{2}, \mathrm{TiO}_{2}$ and $\mathrm{Al}_{2} \mathrm{O}_{3}$ nanofluid respectively. The average value of $220 \mathrm{MJ}$ embodied energy can be saved for each collector, 2.4 years payback period can be achieved and around $170 \mathrm{~kg}$ less $\mathrm{CO}_{2}$ emissions in average can be offset for the nanofluid based solar collector compared to a conventional solar collector. Finally, the environmental damage cost can also be reduced with the nanofluid based solar collector.

Genc et al. [23] introduced a transient heat transfer approach for determining the thermal inertia of each component such as glass, trapped air, absorber and working fluid for nanofluid based flat plate solar collectors. The analyses were carried out with water and three different volumetric concentrations of $\mathrm{Al}_{2} \mathrm{O}_{3}$ nanoparticles as $1 \%, 2 \%$ and $3 \%$. The results indicated that the maximum increase of the outlet temperature is obtained by $7.20 \%$ at $0.004 \mathrm{~kg} / \mathrm{s}$ and $3 \%$ (vol.) mass flow rate and volumetric concentration, respectively, in July. On the other hand, the highest thermal efficiency was obtained as $83.90 \%$ at $0.06 \mathrm{~kg} / \mathrm{s}$ mass flow rate for $1 \%$ (vol.) in October. It was worthy of note that nanofluids can increase the thermal efficiency of the FPSCs at lower flow rates and beyond a critical flow rate the base fluid becomes effective working fluid. The critical flow rate was determined to be $0.016 \mathrm{~kg} / \mathrm{s}$.

Said et al. [24] theoretically analysed entropy generation, heat transfer enhancement capabilities and pres-sure drop for a flat-plate solar collector operated with single wall carbon nanotubes (SWCNTs) based nanofluids as an absorbing medium. The specific heat of the nanofluid was measured using a Perkin Elmer DSC 4000, and a density meter was used to measure the density of the nanofluid. The second law based exergy analysis was carried out to evaluate the efficiency of the flat plate collector. They observed that the SWCNTs nanofluid reduced the entropy generation by $4.34 \%$ and enhance the heat transfer coefficient by $15.33 \%$ theoretically compared to water as an absorbing fluid. Pumping power penalty of nanofluid operated solar collector found to be
$1.20 \%$ higher than the water as a working fluid.

Shamshirgaran et al. [25] investigated the effect of simultaneous using of nanofluid and selective absorber on the improvement of work extraction by a solar flat-plate collector (FPC). A more realistic model for the exergy factor of solar incident was introduced and compared with the Carnot and Petela-Landsberg-Press models. The results demonstrated that exploiting nanofluid rather than pure water could enhance the maximum power generation by the collector since the exergy efficiency boosted by almost $4.1 \%$ at $4 \%$ volume concentration.

Shojaeizadeh et al. [26] investigate the exergy efficiency of a flat-plate solar collector containing $\mathrm{Al}_{2} \mathrm{O}_{3}$-water nanofluid as base fluid. The effect of various parameters like mass flow rate of fluid, nanoparticle volume concentration, collector inlet fluid temperature, solar radiation, and ambient temperature on the collector exergy was investigated. Also, the procedure to determine optimum values of nanoparticle volume concentration, mass flow rate of fluid, and collector inlet fluid temperature for maximum exergy delivery was developed applying interior-point method for constrained optimization under the given conditions. The optimization results indicated that under the actual constraints, in the both pure water and nanofluid cases as working fluids of this solar collector the optimized exergy efficiency is increased with increasing solar radiation value. When nanoparticles were presented in the base fluid, the maximum collector exergy efficiency was increased about $0.72 \%$ and also the corresponding optimized values of mass flow rate and collector inlet fluid temperature were decreased about $67.8 \%, 17 \%$ and $1.9 \%$ respectively.

Sint et al. [27] theoretically analyzed the efficiency of a flat plate solar collector using water based $\mathrm{CuO}$ nanofluid as a working fluid. A mathematical model and a program, written in MATLAB code were used for calculating the efficiency of a flat plate solar collector for a domestic solar water heating system considering weather conditions of a city in Myanmar. This calculation included three aspects. Firstly, the maximum solar energy availability for the flat plate solar collector tilted at the optimum angle was estimated. Secondly, the convective heat transfer coefficient of nanofluid was calculated as a function of volume concentration and size of the nanoparticle. Thirdly, the overall heat loss coefficient of the flat plate solar collector was calculated using a method of iteration. The results showed increasing in collector efficiency by increasing the volume concentration up to $2 \%$ while the effect of nanoparticle size on the efficiency was marginal. The use of the $\mathrm{CuO}$-water nanofluid as a working fluid could improve the efficiency of flat plate solar collector up to $5 \%$ compared with water as a working fluid under the same ambient, radiant and operating conditions.

Tomy et al. [28] analyzed the performance of flat plate solar collector using silver/water nanofluid with the help of artificial neural network in MATLAB. The heat transfer performance such as the outlet temperature, heat transfer coefficient, collector efficiency of the proposed method was confirmed by experimental verification. The analysis showed a very good agreement between the measured and the predicted values for different conditions and flow rates. The results showed the reasonable accuracy when compared with the experimental results of the flat plate solar collector. This can also be used to obtain the efficiency for various mass flow rates without the necessity of carrying out the experimental work. This study demonstrated that an ANN can be used instead of the simulation of mathematical models for solving the complex 
problems.

Khan et al. [29] integrated a solar parabolic dish system with cavity receiver to a recompression $\mathrm{s}-\mathrm{CO}_{2}$ Brayton cycle for power generation. Three oil based nanofluids were introduced in the receiver of dish system to compare the detailed first and second law efficiencies of the integrated CSP system. The influence of change in various operating parameters and conditions were investigated against different performance parameters including, overall energetic and exergetic efficiencies, PDSC efficiency, s- $\mathrm{CO}_{2}$ Brayton cycle efficiency, convection heat transfer and the outlet temperature of the receiver. The results demonstrated that $\mathrm{Al}_{2} \mathrm{O}_{3}$ oil based nanofluid has the highest overall energy and exergy efficiencies, almost $33.73 \%$ and $36.27 \%$, respectively, and is almost $0.27 \%$ more than $\mathrm{TiO}_{2} /$ oil nanofluid and $0.91 \%$ higher than $\mathrm{CuO} /$ oil based nanofluid. The effect of the wind velocity on receiver efficiency was also investigated. By increasing the percentage of nanoparticles, convective heat transfer coefficient of the fluid in the receiver tube also increased. Turbine inlet temperature and pressure ratio was varied to investigate the thermal and exergy efficiencies of the supercritical recompression Brayton cycle.

Korres et al. [30] investigated the use of a nanofluid as the working fluid in a CPC under laminar flow conditions. The studied nanofluid was Syltherm $800 / \mathrm{CuO}$ with $5 \%$ volumetric concentration and it was compared with the thermal oil (Syltherm 800). The results showed that the utilization of nanofluids in CPCs increases the thermal efficiency with a very small penalty in the pumping work. The application of nanofluids was more important in high-temperature levels because of the higher thermal losses and the greater margins for thermal efficiency enhancements in these levels.

Boyaghchi and Chavoshi [31] performed the thermodynamic, economic and environmental analyses of a solar-geothermal driven combined cooling, heating and power (CCHP) cycle integrated with flat plat collectors containing water/copper oxide $(\mathrm{CuO})$ nanofluid as the absorbing medium. Twelve parameters were selected as decision variables and NSGA-II was applied to provide the optimum solutions for four working fluids namely, R134a, R423A, R1234ze and R1234yf. In this study, R134a was the best fluid with $4.194 \%$ daily exergetic efficiency so that the minimum nanoparticle volume fraction was required compared with other studied fluids.

Loni et al. [32] performed a detailed energetic and exergetic analysis of a solar dish concentrator with spiral cavity receiver operating with nanofluids. The analysis was conducted with a developed numerical thermal model which was validated with experimental results. Four different water-based nanofluids were investigated with the following nanoparticles: $\mathrm{Cu}, \mathrm{CuO}$, $\mathrm{TiO}_{2}$ and $\mathrm{Al}_{2} \mathrm{O}_{3}$. The collector performance was examined for different nanoparticle concentration, flow rate and inlet temperature. The analysis was performed using the energy, exergy and entropy generation criteria. According to the final results, the use of $\mathrm{Al}_{2} \mathrm{O}_{3}$ is the best choice thermally, while the use of $\mathrm{CuO}$ is the choice exergetically. The results of this research can be used for designing solar dish collectors and for selecting the proper nanofluid. Moreover, this energetic and exergetic analysis included analytical calculations for various parameters and gave a clear image for the collector energetic and exergetic behavior.

Wang et al. [33] proposed a parabolic trough collector (PTC) system using $\mathrm{Al}_{2} \mathrm{O}_{3}$ /synthetic oil nanofluid as heat transfer fluid (HTF) to improve the performances of the PTC system. They implemented an optic-thermal-stress coupling model to investigate the performances of the proposed PTC system. This research provided a fundamental reference to the application of nanofluid in the PTC system.

Bhalla et al. [34] investigated the effect of five critical factors such as height of the collector, mass flow rate, incident flux, nanoparticle mass fraction, and length of the collector on the performance of nanofluid-based solar collector. The results showed that two factors, i.e., length of the collector, and the incident solar flux, exhibited a strong increasing trend, while one factor, i.e., nanoparticle mass fraction, exhibited an optimizing trend on the output, outlet collector temperature.

AL-Musawi et al. [35] numerically investigated the effects of pure water, $\mathrm{SiO}_{2}$ /water nanofluid, and a phase-change material (PCM) as coolants on the performance of a photovoltaic thermal (PVT) system. Two modules of PVT and PVT/PCM were studied and compared using 3D simulations. The results showed that in the water-based PVT/PCM, the average PV cell temperature is decreased by $16{ }^{\circ} \mathrm{C}$ compared to that of the PVT system. This results in an increase of $8 \%$ in the electrical efficiency and $25 \%$ in the thermal efficiency. In addition, using nanofluid $\left(\mathrm{SiO}_{2}\right.$ with 1 and 3 mass\% mass fraction) as a coolant in the PVT/PCM system increased the thermal efficiency by $3.51 \%$ and $10.40 \%$, for 1 and 3 mass $\%$, respectively, compared to that of the PVT/PCM with pure water as a coolant. This study showed that increasing the melting temperature of the phase-change material leads to an increase in the thermal efficiency of the PVT/PCM system.

Rao et al. [36] studied the boundary layer analysis of nanofluid flow over a bidirectional exponentially stretching sheet in the presence of transverse magnetic field and also in convective condition. The results revealed the existence of interesting Sparrow-Gregg-type Hills for temperature distribution pertinent to some range of parametric values. Moreover the numerical data of drag coefficient, local heat and mass transfer rates were evaluated and analyzed. Effects of local Biot number on temperature and concentration profiles were qualitatively similar. Both the temperature and concentration profiles were enhanced for higher values of local Biot number.

Mehmood et al. [37] presented a mathematical and computational study of the steady, two-dimensional, nonaligned thermo-fluid boundary layer transport of copper metaldoped water-based nano-polymeric sol-gels under radiative heat flux. To simulate real nano-polymer boundary interface dynamics, thermal slip was analysed at the wall. A temperature-dependent viscosity was also considered. The conservation equations for mass, normal and tangential momentum and energy were normalized via appropriate transformations to generate a multi-degree, ordinary differential, nonlinear, coupled boundary value problem. The numerical solutions were obtained via the stable, efficient Runge-Kutta-Fehlberg scheme with shooting quadrature in MATLAB symbolic software. The impact of key emerging dimensionless parameters, i.e. obliqueness parameter, radiation-conduction Rosseland number ( $\mathrm{Rd})$, thermal slip parameter $(\alpha)$, viscosity parameter $(\mathrm{m})$, nanoparticles volume fraction $(\varphi)$, on non-dimensional normal and tangential velocity components, temperature, wall shear stress, local heat flux and streamline distributions was visualized graphically. Shear stress and temperature were boosted with increasing radiative effect, whereas local heat flux was reduced. Increasing wall thermal slip parameter depleted temperatures.

Wakif et al. [38] clearly discussed the effects of thermal 
radiation and magnetic field on the unsteady natural convection Couette flow in $\mathrm{Cu}$-water nanofluids, in the case where the nanofluid is confined between two infinite vertical plates. Moreover, the nanofluid flow was induced by the unsteady motion of the hot plate. Furthermore, the studied nanofluid flow problem was described by the single and twophase nanofluid models in combination with the Corcione's model, which was solved numerically using the GearChebyshev-Gauss-Lobatto collocation method. For both nanofluid models, the effects of major parameters on the dimensionless velocity, temperature and volumetric fraction of nanoparticles were analysed via representative profiles, whereas the skin friction factor and the heat transfer rate were estimated numerically and discussed through tabular illustrations.

Pustovalov and Astafyeva [39] carried out theoretical investigation and selection of the optical properties of homogeneous metallic (titanium $\mathrm{Ti}$, gold $\mathrm{Au}$ ) and metal coreoxide shell $\left(\mathrm{Ti}-\mathrm{TiO}_{2}\right)$ nanoparticles with the radii $50,75,100$ and $125 \mathrm{~nm}$ and their nanofluids in the spectral interval 200$2500 \mathrm{~nm}$ for the purpose of effective absorption of solar radiation. Selected $\mathrm{Ti}$ and $\mathrm{Ti}-\mathrm{TiO}_{2}$ nanoparticles with the radii $75-100 \mathrm{~nm}$, in some cases up to $125 \mathrm{~nm}$, were good absorbers in the visible and infrared spectral intervals and can be proposed for their use in solar thermal systems. Extinction and absorption of solar radiation by nanofluids (nanoparticles and water) were determined by the dominant influence of the system of $\mathrm{Ti}$ and $\mathrm{Ti}+\mathrm{TiO}_{2}$ nanoparticles with concentration $109 \mathrm{~cm}^{-3}$ in the spectral interval $200-800 \mathrm{~nm}$ for the radii $50-$ $75 \mathrm{~nm}$ and in interval $200-1100 \mathrm{~nm}$ for the radii $100-125 \mathrm{~nm}$, and water dominantly influenced the radiation extinction by nanofluid in the spectral range $1200-2500 \mathrm{~nm}$.

Hatami et al. [40] aimed to investigate the heat transfer and fluid flow of peristaltic nanofluids on a two-dimensional sinusoidal wavy channel by least square method (LSM) and differential transformation method (DTM) as two efficient analytical solution methods for solving the nonlinear governing equation. To investigate the heat transfer from this channel, the effects of several parameters appearing in the governing equations on velocity, temperature profiles and nanoparticles concentrations were discussed. An important finding in this study was that, in order to have more nanoparticles concentration around the sinusoidal walls, thermophoresis parameter must be in lower values and vice versa.

Al Kalbani et al. [41] analyzed heat transfer and fluid flow of natural convection in an inclined square enclosure filled with different types of nanofluids having various shapes of nanoparticles in the presence of oriented magnetic field. In the numerical simulations, water, ethylene glycol, and engine oil containing copper, alumina, titanium dioxide nanoparticles were considered. These studies are new and have direct applications in solar thermal collectors and thermal insulator of buildings.

Hussain and Kim [42] discussed the techno-economic impacts of nanofluids used as coolants to enhance the overall performance of a photovoltaic/thermal $\mathrm{PV} / \mathrm{T}$ system, in comparison with conventional fluids. A transient mathematical analysis was performed to evaluate the technical aspects and energy performance of the PV/T system. The proposed model was used to predict the annual thermal and electrical power outputs of a PV/T system based on $\mathrm{CuO}$ nanofluid, $\mathrm{Al}_{2} \mathrm{O}_{3}$ nanofluid, and conventional fluids. Economic and environmental analyses of the PV/T systems were performed by taking into account energy payback period, energy production factor, net $\mathrm{CO}_{2}$ mitigation, and net $\mathrm{CO}_{2}$ credit. Using water, $\mathrm{Al}_{2} \mathrm{O}_{3}$ nanofluid, and $\mathrm{CuO}$ nanofluid, the net $\mathrm{CO}_{2}$ mitigation and net $\mathrm{CO}_{2}$ credit were 6.4 tons and 156.8 USD, 6.9 tons and 171.2 USD, and 7.4 tons and 181.6 USD, respectively, for 30 years life of the PV/T system. For typical industrial applications, PV/T systems with nanofluids should be considered as competitors to water-based PV/T collectors.

Sadripour [43] numerically investigated the effects of using corrugated absorber plate (instead of flat plate) and also using aerosol/carbon-black nanofluid (instead of air) on heat transfer and turbulent flow characteristics in solar collectors. The results revealed that for all times of the year the highest PEC was obtained for corrugated Sinusoidal model; however, the highest temperature increase from inlet to outlet was obtained for rectangular corrugated model. In addition, the results indicated that in sinusoidal model, the nanoparticles volume fractions increase leads to heat performance coefficient increase and the best heat performance conditions were attained in volume fraction of 0.1 per cent and Reynolds number of 4,000 for both six months period. In model with rectangular corrugated plate, usage of nanofluid in all range of Reynolds numbers leaded to reduction of outlet temperature.

Ranga Babu et al. [44] presented an analytical investigation of energy and exergy performance on a solar flat plate collector (SFPC) with $\mathrm{Cu}-\mathrm{CuO} /$ water hybrid nanofluid, $\mathrm{Cu}$ /water and $\mathrm{CuO} /$ water nanofluids as collector running fluids. The heat transfer characteristics, pressure drop, energy and exergy efficiencies SFPC working on these nanofluids were investigated and compared. The collector efficiency was increased by $2.175 \%, 1.05 \%$ and $0.928 \%$ for hybrid nanofluid, $\mathrm{CuO} /$ water and $\mathrm{Cu} /$ water nanofluids respectively, along with a penalty of $2.918 \%, 2.74 \%$ and $3.09 \%$ increase in pressure drop with $\mathrm{Cu}-\mathrm{CuO} /$ water, $\mathrm{CuO} /$ water and $\mathrm{CuO} /$ water nanofluids respectively compared to water.

Anbuchezhian et al. [45] numerically investigated the problem of laminar fluid flow, which results from the stretching of a vertical surface with variable stream conditions in a nanofluid due to solar energy. The model used for the nanofluid incorporated the effects of the Brownian motion and thermophoresis in the presence of thermal stratification. Nanoparticles in the base fluids offer the potential in improving the radiative properties of the liquids, leading to an increase in the efficiency of direct absorption solar collectors.

Anbuchezhian et al. [46] theoretically investigated the MHD convective flow and heat transfer of an incompressible viscous nanofluid past a porous vertical stretching sheet in the presence of variable stream condition due to solar radiation (incident radiation). The absorbed radiation acted as a distributed source which initiates buoyancy-driven flow and convection in the absorbed layer. The partial differential equations governing the problem under consideration were transformed by a special form of Lie symmetry group transformations viz. one-parameter group of transformation into a system of ordinary differential equations which are solved numerically using Runge Kutta Gill based shooting method. The conclusion was drawn that the flow field and temperature are significantly influenced by radiation, heat source and magnetic field.

Bellos et al. [47] presented two usual thermal efficiency enhancements techniques in a linear Fresnel reflector. The use of nanofluids (thermal oil with $\mathrm{CuO}$ up to $6 \%$ ) was compared with the use of internal longitudinal fins in the absorber. Moreover, the combination of these two techniques was 
examined and compared to the other techniques separately. The examined LFR has flat primary reflectors, an evacuated tube receiver and a parabolic shape secondary reflector. The analysis was conducted with Solid-Works Flow Simulation software with a validated model. The use of internal fins was better enhancement method compared to the use of nanofluids, while the combination of these two techniques leads to the highest possible performance.

Bellos and Tzivanidis [48] investigated the utilization of nanofluids in parabolic trough collectors. The module of LS-2 PTC was examined with a developed thermal model in EES. Six different nanoparticles $\left(\mathrm{Cu}, \mathrm{CuO}, \mathrm{Fe}_{2} \mathrm{O}_{3}, \mathrm{TiO}_{2}, \mathrm{Al}_{2} \mathrm{O}_{3}\right.$ and $\mathrm{SiO}_{2}$ ) were examined with Syltherm 800 as the base fluid for concentrations up to $6 \%$. The inlet temperature level, the flow rate and the solar irradiation level were the investigated parameters, as well as the nanoparticle concentration. Moreover, a new evaluation index for the nanofluid evaluation in solar collectors was introduced. The maximum thermal efficiency enhancement was found to be $2.2 \%$ for $6 \% \mathrm{Cu}$ concentration, flow rate $50 \mathrm{~L} \mathrm{~min}-1$ and inlet temperature 600 $\mathrm{K}$. On the other hand, the thermal efficiency enhancement margin for high flow rates and low temperature was approximately negligible.

Goyal and Bhargava [49] carried out a computational study of heat transfer and buoyancy driven fluid flow in nanofluid filled triangular enclosure with slanting wavy wall. A two phase model for nanofluid with Brownian motion and Thermophoresis, the two essential slip mechanisms responsible for enhancing heat transfer in nanofluid were considered. Element Free Galerkin Method with penalty approach was used to solve the problem with parameters such as Rayleigh number, amplitude of wavy wall, Thermophoresis parameter and Brownian motion parameter. This study finds direct application in greenhouse solar collector owing to the roof top structure of greenhouse and the need of controlled temperatures within the greenhouse enclosure.

Fasano and Bigdeli [50] suggested a bottom up approach to systematically explore the thermophysical properties of carbon-based nanofluids with different geometrical, chemical, and physical characteristics. The Prandtl number was suggested as the most adequate parameter for evaluating the best compromise between thermal conductivity and viscosity increases. By comparing the Prandtl number of nanofluids with different characteristics, promising overall performances were observed for semidilute aqueous suspensions of carbon nanoparticles with extreme aspect ratios (larger than 100 for nanotubes, smaller than 0.01 for nanoplatelets) and limited defects concentrations $(<5 \%)$. The bottom up approach discussed in this study may ease a more systematic exploration of carbon-based nanofluids for thermal applications, especially solar ones.

El-Maghlany and Minea [51] reported a numerical study of ([C4mim] [NTf2]) ionic liquid enhanced by adding alumina nanoparticles of different concentration (i.e., volume concentrations of $0.5,1,2.5 \%$, respectively). The considered flow geometry corresponds with one typical used in solar collector applications and consists of a straight tube heated by a constant heat flux applied at tube walls. The ionanofluid properties were chosen by a careful review of the existing literature, and thermophysical properties were adopted variable with temperature variation in order to carefully model the real application as accurate as possible. This pioneering class of heat transfer fluids (ionic liquid-based nanofluids) revealed a great potential in advanced heat transfer applications; therefore, the new correlations aim to collaborate to this progress.

Ghorbanian et al. [52] applied the FlexPDE FEM numerical code to find the solution of 2D modeling of heat transfer for the nanofluids flow in a wavy wall and porous cavity. The results of ANOVA on the proposed experiments by BoxBehnken design (BBD) confirmed that the maximum Nusselt number occurs when all the parameters (wave amplitude, solar heat flux, Darcy number, Rayleigh number) is at its high (+1) levels. Also they observed that in the defined levels, the effect of Darcy and Rayleigh numbers on the Nusselt number as a response function is approximately negligible compared to wave amplitude and heat flux effect.

Khan et al. [53] concentrated on integrating a steam turbine plant to a parabolic trough solar system to analyze the performance of the system by varying certain parameters such as DNI, mass flow rate, ambient and inlet temperature. Al2O3 nanoparticles were mixed with thermal oil, to make nanofluid, which circulates in the collector loop. The results showed that turbines are the main source of exergy destruction $(63855 \mathrm{~kW})$ followed by feed water heaters and boiler. Overall energetic and exergetic efficiencies of the system were observed to be 22.64 and $23.83 \%$, respectively. The integration of PTC system with conventional plant results in a reduction in fuel consumption which significantly brings down the $\mathrm{CO} 2$ emissions by almost $33 \%$.

Ma and Zhang [54] conducted a numerical model based on the Eulerian-Eulerian approach to investigate the heat transfer characteristics of NPCS in a parallel plate channel for volumetric absorption of solar energy. Influences of different parameters such as the extinction coefficient, flow velocity, radiation intensity on the performance of collector were studied through the numerical simulation. The results indicated that the NPCS shows better performance in directly volumetric absorption solar collector compared with the conventional nanofluids without phase change.

Khamis et al. [55] investigated the combined effects of buoyancy force and variable viscosity on unsteady flow and heat transfer of water-based nanofluid containing copper and alumina as nanoparticles through a porous pipe, using the Boussinesq and boundary-layer approximations with Buongiorno nanofluid model. The results showed that with suction, $\mathrm{Cu}$-water produces higher skin friction and heat transfer rate than $\mathrm{Al}_{2} \mathrm{O}_{3}$-water. Both nanofluids velocity and temperature increased with a decrease in viscosity and an increase in buoyancy force intensity.

Meibodi et al. [56] performed a theoretical study based on experimental data to evaluate the second law of thermodynamics for a flat-plate solar collector where $\mathrm{SiO}_{2} /$ EG-water nanofluids with volume fractions up to $1 \%$ were exploited. A new dimensionless entropy generation number was introduced to assess the irreversibility magnitude in the solar collector, i.e., a function of solar radiation and ambient temperature. The analysis was done for three different mass flow rates and different times of the day. They found that when nanofluid concentration increases from 0 to $1 \%$, exergy efficiency enhances up to $62.7 \%$ for a mass flow rate of $1 \mathrm{~L}$ min-1, whereas the corresponding increases in mass flow rates of 1.75 and $2.5 \mathrm{~L} \mathrm{~min}-1$ are 45.2 and $39.7 \%$, respectively. The results also elucidated that entropy generation parameter, which is a function of entropy generation, ambient temperature, and solar radiation, reduces with increasing the nanofluid concentration.

Benabderrahmane et al. [57] presented a three dimensional 
numerical investigation of heat transfer in a parabolic trough collector receiver with longitudinal fins using different kinds of nanofluid, with an operational temperature of $573 \mathrm{~K}$ and nanoparticle concentration of $1 \%$ in volume. The numerical results were contrasted with empirical results available in the open literature. A significant improvement of heat transfer was derived when the Reynolds number varies in the range $2.57 \times 104 \leq \operatorname{Re} \leq 2.57 \times 105$, the tube-side Nusselt number increases from 1.3 to 1.8 times, also the metallic nanoparticles improved heat transfer greatly than other nanoparticles, combining both mechanisms provides better heat transfer and higher thermo-hydraulic performance.

Garg et al. [58] prepared a numerical model for DASC (direct absorption solar collector) -based $\mathrm{HDH}$ (humidification-dehumidification desalination) system which aimed to evaluate the energy efficiency of this combined system by calculating gained output ratio as a function of various parameters, related to the DASC, such as particle volume fraction, height and length of the collector, mass flow rate of nanofluid inside the collector and amount of solar energy incident on the collector. The performance of the combined or integrated system was also verified against the various parameters related to HDH system such as ratio of mass flow rate of the saline water to the dry air, effectiveness of the humidifier and dehumidifier and the bottom temperature. Also the results of the numerical model prepared in this study were compared with those available in the literature. Finally, the applicability and benefits of using nanofluids in various thermal desalination techniques were presented.

Khullar and Tyagi [59] examined the potential of the nanofluid-based concentrating solar water heating system (NCSWHS) as an alternative to systems based on fossil fuels. They reported a quantitative assessment to assess the potential environmental benefits which could be obtained from NCSWHS if substituted for those using fossil fuels. The analysis revealed that considerable emission reductions (about $2.2 \times 103 \mathrm{~kg}$ of $\mathrm{CO}_{2} /$ household/ year) and fuel savings can be achieved if the NCSWHS are adopted.

Pustovalov et al. [60] contained novel information about the light absorption conditions for the selection of nanoparticles and nanofluids under solar radiation with concrete recommendations for their types and parameters that allow using of selected NPs and nanofluids with determined parameters for the nanofluid-based direct absorption solar collectors (DASCs). The nanoparticles with the selected characteristics can realize their effective heating by solar radiation simultaneously and lower than $100{ }^{\circ} \mathrm{C}$ for thermal solar energy applications.

Mohseni-Gharyehsafa et al. [61] performed efforts to optimize the nanofluid turbulent flow inside a circular tube based on the second law of thermodynamics and entropy generation minimization approach, The flow was assumed turbulent, and optimization process was carried out for two metallic oxide nanoparticles $\left(\mathrm{Al}_{2} \mathrm{O}_{3}, \mathrm{CuO}\right)$ and one nonmetallic oxide nanoparticle $\left(\mathrm{SiO}_{2}\right)$, dispersed in a 60:40\% ethylene glycol/water base fluid. The results showed that two metallic oxide nanofluids generate less entropy compared with nonmetallic oxide nanofluid. In addition, comparing these two metallic oxide nanofluids, the maximum amount of total entropy generation was $20 \%$ lower when $\mathrm{CuO}$ nanoparticles added to the base fluid instead of $\mathrm{Al}_{2} \mathrm{O}_{3}$.

Mohamad et al. [62] analyzed the influence of the copper nanoparticles in the presence of magnetic field on unsteady
Hiemenz flow and heat transfer of incompressible $\mathrm{Cu}$ nanofluid along a porous wedge sheet due to solar energy. The conclusion was drawn that the temperature is significantly influenced by magnetic strength, nanoparticle volume fraction, convective radiation and porosity of the wedge sheet.

Matin and Hosseini [63] analytically and numerically investigated the magneto-hydrodynamic (MHD) mixed convection flow of nanofluid over a nonlinear stretching inclined transparent plate embedded in a porous medium under the solar radiation. The effect of various parameters such as nanofluid volume fraction, magnetic parameter, porosity, effective extinction coefficient of porous medium, solar radiation flux, plate inclination angle, diameter of porous medium solid particles and dimensionless Eckert, Richardson and Prandtl numbers was studied on the dimensionless temperature and velocity profiles. Also the results were presented based on Nusselt number and skin friction coefficient.

Rashidi et al. [64] performed the second law of thermodynamics analysis for nanofluid turbulent flow in a solar heater duct with rib roughness on the absorber plate. The effects of different parameters including rib height, rib wedge angle, rib pitch, Reynolds number, and nanofluid concentration on thermal and frictional irreversibilities were investigated. The results indicated that the thermal entropy generation decreases about $11.1 \%$ by using nanofluid with concentration of 0.04 . The frictional and thermal entropy generations decreased by increasing the rib pitch. Moreover, the thermal entropy decreased about $21.05 \%$ by increasing the rib height in the range of $0.025-0.033$ for $R e=3200$. Finally, they found that the thermal entropy generation decreases by increasing the wedge angle of the rib.

Said et al. [65] analyzed the effects of size and concentration of $\mathrm{TiO}_{2}$ nanoparticles on the extinction coefficient using the Rayleigh approach. The results showed that smaller particle size $(<20 \mathrm{~nm})$ has a nominal effect on the optical properties of nanofluids. Volume fraction was linearly proportionate to the extinction coefficient. Considering a nanoparticle size of $20 \mathrm{~nm}$, almost $0 \%$ transmissivity was obtained for wavelengths ranging from 200 to $300 \mathrm{~nm}$. However, a sudden increase of $71 \%$ in transmissivity was noted from $400 \mathrm{~nm}$, gradually increasing to $88 \%$ and becoming similar to that of water at $900 \mathrm{~nm}$. Promising results were observed for volume fractions below $0.1 \%$.

Sami [66] developed a numerical mathematical model to predict the thermal behaviour of thermal solar collectors using nanofluids under different magnetic fields. The model was based upon energy conservation equations for nanofluids flow, heat transfer for different nanofluids and magnetic field. The thermal behaviour of the solar collectors during charging phase was studied, predicted numerically and analysed using different nanofluid materials and magnetic fields. Comparisons were made against literature data for validation purposes of the predictive model. The model fairly predicted heat absorbed and solar panel efficiency under different nanofluids conditions, magnetic fields and compared well with existing data on the subject.

Sekrani et al. [67] investigated the heat transfer performance and entropy generation of water-based $\mathrm{Al}_{2} \mathrm{O}_{3}$ nanofluids flowing within a $2 \mathrm{D}$ channel with a heated wall mounted obstacle. The conjugated heat transfer problem was solved in the laminar regime for Reynolds numbers up to 1600 and nanoparticle volume fractions up to $1.8 \%$. The results showed that only the Reynolds number has an influence on the 
hydrodynamic field, especially on the reattachment length behind the obstacle. The heat transfer rate increased with increasing nanoparticle concentrations and/or Reynolds number. The second law analysis was employed to study the heat transfer and fluid friction irreversibilities. The average entropy generation increased linearly with the Reynolds number. Increasing the nanoparticle volume fraction reduced the thermal entropy generation while the frictional one increases. Finally, the benefit of using this nanofluid was discussed regarding five merit criteria.

Tahari et al. [68] demonstrated the physical effect of a variable magnetic field on a nanofluid-based concentrating parabolic solar collector (NCPSC). A section of reservoir was modeled as a semi-circular cavity under the solar radiation with the magnetic source located in the center or out of the cavity and the governing equations were solved by the FlexPDE numerical software. The effect of four physical parameters, Hartmann Number, nanoparticles volume fraction, magnetic field strength and magnetic source location, on the Nusselt number was discussed. The analysis of variance (ANOVA) of the results revealed that increasing the Hartmann number decreases the Nusselt number due to the Lorentz force resulting from the presence of stronger magnetic field.

Won and Lee [69] analyze the effect of scattering on the performance of the direct absorption solar collector (DASC). The scope of this work also included a parametric study on the absorption coefficient and channel height because scattering does not independently affect the performance of solar collector. In addition, the Monte Carlo method was employed to numerically solve the radiative transfer equation considering the volume scattering inside the nanofluid. The results obtained with the Monte Carlo method were volumetric heat generation in the solar collector and solar-weighted absorption coefficient. The calculated heat generation was incorporated into a two-dimensional heat transfer model for the solar collector using Open FOAM. They found that the light scattering can improve the collector performance if the scattering coefficient of nanofluid is carefully engineered depending on its value of the absorption coefficient.

Uddin et al. [70] studied the problem of two-dimensional transient convective flow and heat transfer in nanofluids in a quarter-circular-shaped enclosure using newly proposed nonhomogeneous dynamic mathematical model. The result showed that 1 - to 10 -nm-sized nanoparticles are uniform and stable in the solution. The external magnetic field and its direction controlled the flow pattern of nanofluid significantly. The average Nusselt number increased significantly, as nanoparticle volume fraction, magnetic field inclination angle and Rayleigh number increase. Average Nusselt number of cobalt-kerosene nanofluid was much higher than other 17 types of nanofluids studied. The flow behaviors and the heat transfer rates of 18 types of nanofluids were presented for the scientific and engineering community to become familiar with such nanofluids and apply them in practical applications.

Nasrin et al. [71] presented a numerical visualization of heat transport for forced convective heat transfer by a twodimensional heat function formulation through a direct absorption solar collector (DASC) filled with water-copper nanofluid. The penalty finite element method was used to solve nonlinear partial differential equations, and the numerical results were presented for variations in the radiative heat flux, Prandtl number, particle diameter, and solid volume fraction of the nanoparticle. Generally, a DASC performed better than a flat-plate collector; however, much better designed flat-plate collectors might be able to match or outperform the efficiency of a nanofluid-based DASC under certain conditions.

Pustovalov [72] reported an investigation of the modeling of the heating dynamics of single homogeneous and core-shell nanoparticles, their assemblies and surrounding medium (fluid) by solar radiation allowing to select their parameters for effective applications. The influence of the concentrations, sizes and other parameters of nanoparticles on dynamics and the results of solar heating were established. These studies were highlighting the importance of the use of established remarkable approaches that can improve current solar thermal technologies in near future.

Rahman et al. [73] numerically carried out with an accurate numerical procedure, and the related results were shown using streamlines, isotherms, and related graphs and charts. The results showed that the augmentation of heat transfer is possible by introducing nanofluid inside the collector.

Zhang et al. [74] developed a new theoretical model for the thermal conductivity of nanofluids incorporating effective medium theory, interfacial layer, particle aggregation and Brownian motion-induced convection from multiple nanoparticles/aggregates. The predication result using aggregate size, which represents the particle size in the actual condition of nanofluids, showed a good agreement with the experimental results and also gives much better predictions compared to the existing models.

Tullius and Bayazitoglu [75] proposed the use of a hybrid nanofluid containing multiple types of nanoparticles with water as the base fluid exposed to radiation. This hybrid mixture can utilize a broader wavelength spectrum and absorb more heat. The recipes for combining gold, copper, aluminum, graphite, and silicon dioxide gold nanoparticles into water were given graphically and numerically for different concentrations, diameters, and container heights.

Sheikh et al. [76] analyzed the influence of different nanoparticles on the heat transfer rate of the fluid and its applications in the enhancement of the performance of solar collectors using the two different generalized fluid models, i.e. $\mathrm{CF}$ (Caputo-Fabrizio) and $\mathrm{AB}$ (Atangana-Baleanu) fractional models. A comparative analysis of both the fractional derivatives models $\mathrm{CF}$ and a newly introduced definition, $\mathrm{AB}$ was also presented. As a special case the solutions corresponding to the classical model of nanofluids were also recovered. Theoretical results showed that by adding aluminum oxide nanoparticles, the efficiency of solar collectors may be enhanced by $5.2 \%$. Furthermore, the effect of volume friction of nanoparticles on velocity distribution was discussed in graphical illustrations. The solutions were reduced to the corresponding classical model of nanofluid.

Pustovalov and Astafyeva [77] reported a comparative analysis of optimal parameters of various metallic nanoparticles for their use as photo-thermal agents in solar nanotechnologies in the spectral range of 250-2500 nm, which constitutes $95 \%$ of the solar radiation energy spectrum. The influence of the parameters of nanoparticles (radius, nanoparticle shell thickness, etc.) and of the surrounding liquid (water) on the optical-absorption, scattering, and radiationextinction cross sections of nanoparticles was investigated. They found that, for certain values of the particle radius, $\mathrm{Ti}+$ $\mathrm{TiO}_{2}$ and $\mathrm{Ni}+\mathrm{NiO}$ nanoparticles are good radiation absorbers, especially in the ultraviolet, visible, and near infrared spectral ranges, and they can be used for purposes of solar-thermal energetics. 
Minea and Moldoveanu [78] performed a comprehensive analysis to evaluate the effects on the performance of nanofluids due to variations of density, specific heat, thermal conductivity and viscosity, which are functions of nanoparticle volume concentration. Three metallic oxides, aluminum oxide $\left(\mathrm{Al}_{2} \mathrm{O}_{3}\right)$, copper oxide $(\mathrm{CuO})$, and titanium dioxide $\left(\mathrm{TiO}_{2}\right)$, dispersed in water as the base fluid were studied. A convenient figure of merit, known as the Mouromtseff number, was used as a base of comparisonfor laminar and turbulent flows. The results indicated that the considered nanofluids can successfully replace water in specific applications for a singlephase forced convection flow in a tube.

Mercatelli et al. [79] investigated the scattering and spectrally resolved absorption properties of nanofluids consisting in aqueous and glycol suspensions of single-wall carbon nanohorns. The characteristics of these nanofluids were evaluated in view of their use as sunlight absorber fluids in a solar device. The observed nanoparticle-induced differences in optical properties appeared promising, leading to a considerably higher sunlight absorption with respect to the pure base fluids. They demonstrated that only small amount of radiation $(\sim 5 \%$ of the total extinction) was scattered by SWCNH particles and therefore the absorption effect was strongly prevailing. Moreover, the small scattering was also combined with an overall high absorption level at the sunlight emission wavelengths. Both these effects make SWCNHsbased nanofluids very appealing as direct absorbers in innovative solar collectors. The reported scattering and absorption properties can be used in simulations and nanofluid optimization.

Kaya and Arslan [80] numerically designed and simulated an evacuated U-tube tube solar collector (EUSC). The thermal performance of the EUSC was analyzed under different operating conditions. In order to enhance the heat transfer efficiency and also collector efficiency, higher thermal conductivity working fluids were used. $\mathrm{Ag}, \mathrm{ZnO}$ and $\mathrm{MgO}$ nanoparticles in 30 \%:70 \% (by volume) ethylene glycol-pure water (EG-PW) mixture and different nanoparticle volumetric concentrations were used as working fluids. The highest collector efficiency was found at $68.7 \%$ for $4.0 \mathrm{vol} \% \mathrm{Ag} / \mathrm{EG}-$ PW nanofluid which is $26.7 \%$ higher than EG- PW. Furthermore, using nanofluids in solar collectors helps to reduce the coal usage with $\mathrm{CO}_{2}$ and $\mathrm{SO}_{2}$ generation. The maximum values of reduction of coal usage and $\mathrm{CO}_{2}$ and $\mathrm{SO}_{2}$ generation were $855.5 \mathrm{~kg}, 2241.4 \mathrm{~kg}$ and $7.2 \mathrm{~kg}$ per year, respectively, when 30 solar collectors are installed with using $4.0 \mathrm{vol} \% \mathrm{Ag} / \mathrm{EG}-\mathrm{PW}$ nanofluid. These findings revealed that the using of solar energy comprehensively is more beneficial for health of earth.

Akhatov et al. [81] reported the simulation results of the thermal performances of flat-plate solar collector with heat transfer fluid-nanofluid $\left(\mathrm{SiO}_{2}+\right.$ water with $5 \%$ concentration). The dependence of the outlet temperature and gained useful energy of heat transfer fluid (nanofluid) on the flow rates (10, 15 and $20 \mathrm{~L} / \mathrm{h}$ ) at different ranges of incident solar radiation (500-1000 W/m²) was obtained.

Sadripour and Chamkha [82] investigated the effects of different morphology of supported nanoparticles, including copper, silver, aluminum dioxide, boehmite alumina, molybdenum disulfide and silicon dioxide, on heat transfer and entropy generation have been in compression with each other in case of a water-based heat sink solar collector located in Isfahan city, Iran. The maximum value of outlet temperature was achieved for Ag nanoparticles with sphere shape in $\varphi=$
$0.15 \%$, and it was followed by $\mathrm{Cu}$ with sphere shape in $\varphi=0.20 \%, \mathrm{MoS}_{2}$ with sphere shape in $\varphi=4 \%, \mathrm{Al}_{2} \mathrm{O}_{3}$ with sphere shape in $\varphi=4 \%, \mathrm{SiO}_{2}$ with sphere shape in $\varphi=4 \%$ and $\gamma$-AlOOH with sphere shape in $\varphi=4 \%$.

Chamkha and Selimefendigil [83] performed a numerical simulation of a PV-thermal module with $\mathrm{SiO}_{2}$-water nanofluid. They observed that cylindrical shape particles give the best performance in terms of efficiency enhancement. Total PV/T module efficiency enhances by about $7.39 \%$ at the highest volume fraction with cylindrical shape particles. As compared to spherical ones, up to $4 \%$ more in the efficiency enhancement was observed with cylindrical shape particles. Thermal and total efficiency increase for higher solid particle volume fraction, higher values of solar irradiation, lower values of convective heat transfer coefficient and inlet temperature. Adding nanoparticles was advantageous for the case where convective heat transfer coefficient is high. Finally, correlation based on radial basis artificial neural networks was obtained for thermal and PV-efficiency of the PV-thermal module. The performance characteristics of solar PV-thermal module with ANN were compared with those obtained using the CFD modeling and were to be in excellent agreement.

Chamkha and Dogonchi [84] numerically examined the natural convection of a magnetohydrodynamic nanofluid in an enclosure subject to the effects of thermal radiation and the shape factor of nanoparticles using the control-volume-based finite element method (CVFEM). The investigation of nanofluid heat transfer and flow was conducted using an extensive range of Rayleigh numbers, radiation parameters, nanofluid volume fractions, Hartmann numbers, and nanoparticle shape factors. The outcomes indicated that the local and average Nusselt numbers increase with increasing Rayleigh number, radiation parameter, and nanofluid volume fraction, while they decrease with decreasing Hartmann number. Moreover, the laminar nanoparticle has a higher local Nusselt than the other nanoparticle shapes.

Razmmand et al. [85] numerically investigated the effects of adding nanoparticles to the pure water. Silver, aluminum, gold, nickel and titanium dioxide were considered in this study. The results showed that the distance at which the critical heat flux occurs, (known as critical length) is improved significantly by adding various concentrations of mentioned nanoparticles, and especially for $\mathrm{Au}-\mathrm{H}_{2} \mathrm{O}$ and $\mathrm{Al}-\mathrm{H}_{2} \mathrm{O}$ nanofluids in a volume concentration of $2 \%$, the calculated values are respectively 2.7 and 2.3 times the critical length for the pure water.

Chen et al. [86] carried out a one-dimensional transient heat transfer analysis to analyze the effects of the Nanoparticle (NP) volume fraction, collector height, irradiation time, solar flux, and NP material on the collector efficiency. The numerical results were compared with the experimental results obtained by silver nanofluids to validate the model, and good agreement was obtained.

Balakin et al. [87] presented a Eulerian-Eulerian two-phase CFD-model of the direct absorption solar collector with nanofluid. The model was capable of reproducing motion and heat transfer in each separate phase: the base fluid (continuous) and the nanoparticles (dispersed). The particulate phase follows the base fluid via the inter-phase momentum transfer and Brownian terms. The model was validated with the third-party experimental data, demonstrating satisfactory agreement. 


\section{CONCLUSION}

The current paper is a comprehensive literature review on various research works through this topic. Thus, data of different numerical studies employing several types and assumptions for various kinds of nanofluids and different geometries for solar collector, i.e. low temperature application non-concentrating (unglazed/glazed flat plates, solar ponds, and evacuated tubes with/without heat pipes), and high temperature application concentrating (non-tracking, single axis tracking, and two axes tracking), are brought together. This paper reviewed the numerical studies implemented on nanofluids including traditional and novel approaches. The research works performed employing techniques such as conventional single-phase method, dispersion single-phase method, Lattice Boltzmann method, Eulerian-Eulerian methods including mixture model, Eulerian, and volume of fluid (VOF), Eulerian-Lagrangian Method, etc. Recently, nanofluids have been increasingly used in different solar collector configurations. Nano-sized metallic or non-metallic particles such as $\mathrm{Cu}, \mathrm{Au}, \mathrm{Al}_{2} \mathrm{O}_{3}, \mathrm{SiO}_{2}, \mathrm{TiO}_{2}$ and $\mathrm{CuO}$ were used in the heat transfer fluid for various solid volume fractions. The average size of the particles was less than 100 $\mathrm{nm}$. The higher conductivity of nanoparticles even at low particle concentration results in higher thermal conductivity of the base fluid and improves the thermal characteristics of the system. Nanoparticle size, type and shape are important factors for the thermal conductivity enhancement of the nanofluid with nanoparticles.

\section{REFERENCES}

[1] Choi, S.U.S., Eastman, J.A. (1995). Enhancing thermal conductivity of fluid with nanoparticles. In Proceedings of 1995 ASME International Mechanical Engineering Congress and Exhibition, San Francisco, CA, USA, pp. 12-17.

[2] Aminossadati, S.M., Ghasemi, B. (2005). The effects of orientation of an inclined enclosure on laminar natural convection. Int. J. Heat Technol, 23: 43-49.

[3] Ghasemi, B., Aminossadati, S.M. (2010). Brownian motion of nanoparticles in a triangular enclosure with natural convection. Int. J. Therm. Sci, 49: 931-940. https://doi.org/10.1016/j.ijthermalsci.2009.12.017

[4] Abu-Nada, E., Chamkha, A.J. (2010). Effect of nanofluid variable properties on natural convection in enclosures filled with a $\mathrm{CuO}-\mathrm{EG}-$ water nanofluid. Int. J. Therm. Sci. 49:

2339-2352.

https://doi.org/10.1016/j.ijthermalsci.2010.07.006

[5] Nemati, H., Frhadi, M., Sedighi, K., Ashorynejad, H.R., Fattahi, E. (2012). Magnetic field effects on natural convection flow of nanofluid in a rectangular cavity using the Lattice Boltzmann model. Sci. Iran, 19: 303310. https://doi.org/10.1016/j.scient.2012.02.016

[6] Mahmoudi, A.H., Pop, I., Shahi, M. (2012). Effect of magnetic field on natural convection in a triangular enclosure filled with nanofluid. Int. J. Therm. Sci, 59: 126-140.

https://doi.org/10.1016/j.ijthermalsci.2012.04.006

[7] Habibi, M.M., Pop, I. (2013). Natural convection flow and heat transfer in an eccentric annulus filled by Copper nanofluid. Int. J. Heat Mass Transf, 61: 353-364 https://doi.org/10.1016/j.ijheatmasstransfer.2013.01.061
[8] Sheikhzadeh, G.A., Dastmalchi, M., Khorasanizadeh, H. (2013). Effects of nanoparticles transport mechanisms on $\mathrm{Al}_{2} \mathrm{O}_{3}$-water nanofluid natural convection in a square enclosure. Int. J. Therm. Sci, 66: 51-62. https://doi.org/10.1016/j.ijthermalsci.2012.12.001

[9] Sheikholeslami, M., Gorji-Bandpy, M., Seyyedi, S.M., Ganji, D.D., Rokni, H.B., Soleimani, S. (2013). Application of LBM in simulation of natural convection in a nanofluid filled square cavity with curve boundaries. Powder Technol, 247: 87-94. https://doi.org/10.1016/j.powtec.2013.06.008

[10] Sheikholeslami, M., Gorji-Bandpy, M., Ellahi, R., Zeeshan, A. (2014). Simulation of MHD CuO-water nanofluid flow and convective heat transfer considering Lorentz forces. J. Magn. Magn. Mater, 369: 69-80. https://doi.org/10.1016/j.jmmm.2014.06.017

[11] Ajeel, R.K., Salim, W.S.I.W., Hasnan, K. (2019). Design characteristics of symmetrical semicircle-corrugated channel on heat transfer enhancement with nanofluid. International Journal of Mechanical Sciences, 151: 236250. https://doi.org/10.1016/j.ijmecsci.2018.11.022

[12] Ajeel, R.K., Saiful-Islam, W., Hasnan, K.B. (2018). Thermal and hydraulic characteristics of turbulent nanofluids flow in trapezoidal-corrugated channel: Symmetry and zigzag shaped. Case Studies in Thermal Engineering, 12: 620-635. https://doi.org/10.1016/j.csite.2018.08.002

[13] Bezaatpour, M., Goharkhah, M. (2018). Three dimensional simulation of hydrodynamic and heat transfer behavior of magnetite nanofluid flow in circular and rectangular channel heat sinks filled with porous media. Powder Technology, 344: 68-78. https://doi.org/10.1016/j.powtec.2018.11.104

[14] Dormohammadi, R., Farzaneh-Gord, M., EbrahimiMoghadam, A., Ahmadi, M.H. (2018). Heat transfer and entropy generation of the nanofluid flow inside sinusoidal wavy channels. Journal of Molecular Liquids, 269:

229-240. https://doi.org/10.1016/j.molliq.2018.07.119

[15] Joseph, M., Sajith, V. (2018). An investigation on heat transfer performance of polystyrene encapsulated noctadecane based nanofluid in square channel. Applied Thermal Engineering, 147: 756-769. https://doi.org/10.1016/j.applthermaleng.2018.10.120

[16] Minakov, A.V., Guzei, D.V., Meshkov, K.N., Popov, I.A., Shchelchkov, A.V. (2017). Experimental study of turbulent forced convection of nanofluid in channels with cylindrical and spherical hollows. International Journal of Heat and Mass Transfer, 115: 915-925. https://doi.org/10.1016/j.ijheatmasstransfer.2017.07.117

[17] Mohebbi, R., Rashidi, M.M., Izadi, M., Sidik, N.A.C., Xian, H.W. (2018). Forced convection of nanofluids in an extended surfaces channel using lattice Boltzmann method. International Journal of Heat and Mass Transfer, 117:

1291-1303. https://doi.org/10.1016/j.ijheatmasstransfer.2017.10.063

[18] Ameri, M., Eshaghi, M.S. (2018). Exergy and thermal assessment of a Novel system utilizing flat plate collector with the application of nanofluid in porous media at a constant magnetic field. Thermal Science and Engineering Progress, 8: 223-235. https://doi.org/10.1016/j.tsep.2018.08.004

[19] Bazdidi-Tehrani, F., Khabazipur, A., Vasefi, S.I. (2018). Flow and heat transfer analysis of $\mathrm{TiO}_{2} /$ water nanofluid 
in a ribbed flat-plate solar collector. Renewable Energy, 122: 406-418. https://doi.org/10.1016/j.renene.2018.01.056

[20] Bellos, E., Tzivanidis, C. (2018). Performance analysis and optimization of an absorption chiller driven by nanofluid based solar flat plate collector. Journal of Cleaner Production, 174: 256-272. https://doi.org/10.1016/j.jclepro.2017.10.313

[21] Edalatpour, M., Solano, J.P. (2017). Thermal-hydraulic characteristics and exergy performance in tube-on-sheet flat plate solar collectors: effects of nanofluids and mixed convection. International Journal of Thermal Sciences, 118: 397-409. https://doi.org/10.1016/j.ijthermalsci.2017.05.004

[22] Faizal, M., Saidur, R., Mekhilef, S., Alim, M.A. (2013). Energy, economic and environmental analysis of metal oxides nanofluid for flat-plate solar collector. Energy Conversion and Management, 76: 162-168. https://doi.org/10.1016/j.enconman.2013.07.038

[23] Genc, A.M., Ezan, M.A., Turgut, A. (2018). Thermal performance of a nanofluid-based flat plate solar collector: A transient numerical study. Applied Thermal Engineering, 130: 395-407. https://doi.org/10.1016/j.applthermaleng.2017.10.166

[24] Said, Z., Saidur, R., Rahim, N.A., Alim, M.A. (2014). Analyses of exergy efficiency and pumping power for a conventional flat plate solar collector using SWCNTs based nanofluid. Energy and Buildings, 78: 1-9. https://doi.org/10.1016/j.enbuild.2014.03.061

[25] Shamshirgaran, S.R., Assadi, M.K., Badescu, V., AlKayiem, H.H. (2018). Upper limits for the work extraction by nanofluid-filled selective flat-plate solar collectors. $\quad$ Energy, 160 : 875-885. https://doi.org/10.1016/j.energy.2018.06.154

[26] Shojaeizadeh, E., Veysi, F., Kamandi, A. (2015). Exergy efficiency investigation and optimization of an $\mathrm{Al}_{2} \mathrm{O}_{3}$ water nanofluid based flat-plate solar collector. Energy and Buildings, 101: 12-23. https://doi.org/10.1016/j.enbuild.2015.04.048

[27] Sint, N.K.C., Choudhury, I.A., Masjuki, H.H., Aoyama, H. (2017). Theoretical analysis to determine the efficiency of a $\mathrm{CuO}$-water nanofluid based-flat plate solar collector for domestic solar water heating system in Myanmar. Solar Energy, 155: 608-619. https://doi.org/10.1016/j.solener.2017.06.055

[28] Tomy, A.M., Ahammed, N., Subathra, M.S.P., Asirvatham, L.G. (2016). Analysing the performance of a flat plate solar collector with silver/water nanofluid using artificial neural network. Procedia Computer Science, $\quad$ 93: 33-40. https://doi.org/10.1016/j.procs.2016.07.178

[29] Khan, M.S., Abid, M., Ali, H.M., Amber, K.P., Bashir, M.A., Javed, S. (2019). Comparative performance assessment of solar dish assisted $\mathrm{s}-\mathrm{CO}_{2}$ Brayton cycle using nanofluids. Applied Thermal Engineering, 148: 295-306

https://doi.org/10.1016/j.applthermaleng.2018.11.021

[30] Korres, D., Bellos, E., Tzivanidis, C. (2018). Investigation of a nanofluid-based compound parabolic trough solar collector under laminar flow conditions. Applied Thermal Engineering, 149: 366-376. https://doi.org/10.1016/j.applthermaleng.2018.12.077

[31] Boyaghchi, F.A., Chavoshi, M. (2017). Multi-criteria optimization of a micro solar-geothermal CCHP system applying water/CuO nanofluid based on exergy. exergoeconomic and exergoenviron-mental concepts, Applied Thermal Engineering, 112: 660-675. https://doi.org/10.1016/j.applthermaleng.2016.10.139

[32] Loni, R., Pavlovic, S., Bellos, E., Tzivanidis, C., AsliArdeh, E.A. (2018). Thermal and exergy performance of a nanofluid-based solar dish collector with spiral cavity receiver. Applied Thermal Engineering, 135: 206-217. https://doi.org/10.1016/j.applthermaleng.2018.02.070

[33] Wang, Y., Xu, J., Liu, Q., Chen, Y., Liu, H. (2016). Performance analysis of a parabolic trough solar collector using $\mathrm{Al}_{2} \mathrm{O}_{3}$ /synthetic oil nanofluid. Applied Thermal Engineering, 107: 469-478. https://doi.org/10.1016/j.applthermaleng.2016.06.170

[34] Bhalla, V., Khullar, V., Tyagi, H. (2019). Investigation of factors influencing the performance of nanofluid based direct absorption solar collector using Taguchi method. Journal of Thermal Analysis and Calorimetry, 135: 1493-1505. https://doi.org/10.1007/s10973-0187721-x

[35] AL-Musawi, A.I.A., Taheri, A., Farzanehnia, A., Sardarabadi, M., Passandideh-Fard, M. (2018). Numerical study of the effects of nanofluids and phasechange materials in photovoltaic thermal (PVT) systems. Journal of Thermal Analysis and Calorimetry, 137: 623636. https://doi.org/10.1007/s10973-018-7972-6

[36] Rao, M.V.S., Gangadhar, K., Varma, P.L.N. (2018). A spectral relaxation method for three-dimensional MHD flow of nanofluid flow over an exponentially stretching sheet due to convective heating: An application to solar energy. Indian J Phys, 92: 1577-1588. https://doi.org/10.1007/s12648-018-1226-0

[37] Mehmood, R., Tabassum, R., Kuharat, S., Anwar Bég O., Babaie, M. (2018). Thermal slip in oblique radiative nano-polymer gel transport with temperature-dependent viscosity: solar collector nanomaterial coating manufacturing simulation. Arabian Journal for Science and Engineering, 44: 1525-1541. https://doi.org/10.1007/s13369-018-3599-y.

[38] Wakif, A., Boulahia, Z., Ali, F., Eid, M.R., Sehaqui, R. (2018). Numerical analysis of the unsteady natural convection MHD Couette nanofluid flow in the presence of thermal radiation using single and two-phase nanofluid models for $\mathrm{Cu}$-Water Nanofluids. Int. J. Appl. Comput. Math, 4(3): 81. https://doi.org/10.1007/s40819018-0513-y

[39] Pustovalov, V.K., Astafyeva, L.G. (2018). Optical properties of nanoparticles and nanofluids for direct absorption of solar radiation. Nanotechnology for Environmental Engineering, 3(1): 15. https://doi.org/10.1007/s41204-018-0044-0

[40] Hatami, M., Mosayebidorcheh, S., Jing, D. (2018). Peristaltic flow and heat transfer of nanofluids in a sinusoidal wall channel: two-phase analytical study. The Journal of Analysis, 1-17. https://doi.org/10.1007/s41478-018-0154-X

[41] Al Kalbani, K.S., Rahman, M.M., Alam ,M.D.S. (2018). Buoyancy induced heat transfer flow inside a tilted square enclosure filled with nanofluids in the presence of oriented magnetic field. Heat Transfer Engineering, 39(6):

511-525. https://doi.org/10.1080/01457632.2017.1320164

[42] Hussain, M.I., Kim, J.T. (2018). Conventional fluid- and nanofluid-based photovoltaic thermal (PV/T) systems: A 
techno-economic and environmental analysis, International Journal of Green Energy, 15(11): 596-604. https://doi.org/10.1080/15435075.2018.1525558

[43] Sadripour, S. (2019). 3D numerical analysis of atmospheric-aerosol/carbon-black nanofluid flow within a solar air heater located in Shiraz, Iran. International Journal of Numerical Methods for Heat \& Fluid Flow, 29(4): 1378-1402. https://doi.org/10.1108/HFF-042018-0169.

[44] Ranga Babu, J., Kiran Kumar, K., Srinivasa Rao, S. (2018). Thermodynamic analysis of hybrid nanofluid based solar flat plate collector. World Journal of Engineering, 15(1): 27-39. https://doi.org/10.1108/WJE03-2017-0048

[45] Anbuchezhian, N., Srinivasan, K., Chandrasekaran, K., Kandasamy, R. (2012). Thermophoresis and Brownian motion effects on boundary layer flow of nanofluid in presence of thermal stratification due to solar energy. Appl. Math. Mech. -Engl. Ed, 33(6): 765-780. https://doi.org/10.1007/s10483-012-1585-8

[46] Anbuchezhian, N., Srinivasan, K., Chandrasekaran, K., Kandasamy, R. (2013). Magnetohydrodynamic effects on natural convection flow of a nanofluid in the presence of heat source due to solar energy. Meccanica, 48: $307-$ 321. https://doi.org/10.1007/s11012-012-9602-x

[47] Bellos, E., Tzivanidis, C., Papadopoulos, A. (2019). Enhancing the performance of a linear Fresnel reflector using nanofluids and internal finned absorber. Journal of Thermal Analysis and Calorimetry, 135(1): 237-255. https://doi.org/10.1007/s10973-018-6989-1

[48] Bellos, E., Tzivanidis, C. (2019). Thermal efficiency enhancement of nanofluid-based parabolic trough collectors. Journal of Thermal Analysis and Calorimetry, 135(1): 597-608. https://doi.org/10.1007/s10973-0187056-7.

[49] Goyal, R., Bhargava, R. (2017). Meshfree simulation of thermodiffusion effects in a nanofluid filled triangular enclosure with slanting wavy wall with application to greenhouse solar collector. Int. J. Appl. Comput. Math, 3(1): 243-259. https://doi.org/10.1007/s40819-0170354-0

[50] Fasano, M., Bigdeli, M.B. (2018). Bottom up approach toward prediction of effective thermophysical properties of carbon-based nanofluids. Heat Transfer Engineering, 39(19): 1686-1697. https://doi.org/10.1080/01457632.2017.1384283

[51] El-Maghlany, W.M., Minea, A.A. (2019). Novel empirical correlation for ionanofluid PEC inside tube subjected to heat flux with application to solar energy. Journal of Thermal Analysis and Calorimetry, 135(2): 1161-1170. https://doi.org/10.1007/s10973-018-7461-y

[52] Ghorbanian, A., Tahari, M., Hatami, M. (2017). Physical optimization of a wavy porous cavity filled by nanofluids in the presence of solar radiations using the BoxBehnken design (BBD). Eur. Phys. J. Plus, 132(6): 278. https://doi.org/10.1140/epjp/i2017-11583-8

[53] Khan, M.S., Abid, M., Ratlamwala, T.A.H. (2019). Energy, exergy and economic feasibility analyses of a 60 MW conventional steam power plant integrated with parabolic trough solar collectors using nanofluids. Iran J Sci Technol Trans Mech Eng., 43(1): 193-209. https://doi.org/10.1007/s40997-018-0149-x

[54] Ma, F., Zhang, P. (2018). Heat transfer characteristics of a volumetric absorption solar collector using nano- encapsulated phase change slurry. Heat Transfer Engineering, $\quad 39(17-18)$ : 1487-1497. https://doi.org/10.1080/01457632.2017.1369827

[55] Khamis, S., Makinde, D.O., Nkansah-Gyekye, Y. (2015). Unsteady flow of variable viscosity $\mathrm{Cu}$-water and $\mathrm{Al}_{2} \mathrm{O}_{3}$ water nanofluids in a porous pipe with buoyancy force. International Journal of Numerical Methods for Heat \& $\begin{array}{lll}\text { Fluid } & \text { Flow, 25(7): 1638-1657. }\end{array}$ https://doi.org/10.1108/HFF-09-2014-0286

[56] Meibodi, S.S., Kianifar, A., Mahian, O., Wongwises, S. (2016). Second law analysis of a nanofluid-based solar collector using experimental data. J. Therm. Anal. Calorim, 126: 617-625. https://doi.org/10.1007/s10973016-5522-7

[57] Benabderrahmane, A., Aminallah, M., Laouedj, S., Benazza, A., Solano, J.P. (2016). Heat transfer enhancement in a parabolic trough solar receiver using longitudinal fins and nanofluids. Journal of Thermal Science, 25(5): 410-417. https://doi.org/10.1007/s11630016-0878-3

[58] Garg, K., Khullar, V., Das, S.K., Tyagi, H. (2019). Parametric study of the energy efficiency of the $\mathrm{HDH}$ desalination unit integrated with nanofluid-based solar collector. Journal of Thermal Analysis and Calorimetry, 135(2): 1465-1478. https://doi.org/10.1007/s10973-0187547-6

[59] Khullar. V., Tyagi, H. (2012). A study on environmental impact of nanofluid based concentrating solar water heating system. International Journal of Environmental Studies, 69(2): 220-232. https://doi.org/10.1080/00207233.2012.663227

[60] Pustovalov, V.K., Astafyeva, L.G., Fritzsche, W. (2017). Light-absorption selection of nanoparticles and nanofluids containing nanoparticles for their effective heating by solar radiation. Nanotechnol. Environ. Eng., 2(1): 7. https://doi.org/10.1007/s41204-017-0019-6

[61] Mohseni-Gharyehsafa, B., Ebrahimi-Moghadam, A., Okati, V., Farzaneh-Gord, M., Ahmadi, M.H., Lorenzini, G. (2019). Optimizing flow properties of the different nanofluids inside a circular tube by using entropy generation minimization approach. Journal of Thermal Analysis and Calorimetry, 135(1): 801-811. https://doi.org/10.1007/s10973-018-7276-X.

[62] Mohamad, R.B., Kandasamy, R., Muhaimin, I. (2013). Enhance of heat transfer on unsteady Hiemenz flow of nanofluid over a porous wedge with heat source/sink due to solar energy radiation with variable stream condition. Heat Mass Transfer, 49: 1261-1269. https://doi.org/10.1007/s00231-013-1163-6

[63] Matin, M.H., Hosseini, R. (2014). Solar radiation assisted mixed convection MHD flow of nanofluids over an inclined transparent plate embedded in a porous medium. Journal of Mechanical Science and Technology, 28(9): 3885-3893. https://doi.org/10.1007/s12206-0140852-5

[64] Rashidi, S., Javadi, P., Esfahani, J.A. (2019). Second law of thermodynamics analysis for nanofluid turbulent flow inside a solar heater with the ribbed absorber plate. Journal of Thermal Analysis and Calorimetry, 135(1): 551-563. https://doi.org/10.1007/s10973-018-7164-4.

[65] Said, Z., Sajid, M.H., Saidur, R., Mahdiraji, G.A., Rahim, N.A. (2015). Evaluating the optical properties of $\mathrm{TiO}_{2}$ nanofluid for a direct absorption solar collector. Numerical Heat Transfer, Part A, 67: 1010-1027. 
https://doi.org/10.1080/10407782.2014.955344

[66] Sami, S. (2018). Impact of magnetic field on the enhancement of performance of thermal solar collectors using nanofluids. International Journal of Ambient Energy,

$1-10$. https://doi.org/10.1080/01430750.2018.1437561

[67] Sekrani, G., Poncet, S., Proulx, P. (2019). Conjugated heat transfer and entropy generation of $\mathrm{Al}_{2} \mathrm{O}_{3}$-water nanofluid flows over a heated wall-mounted obstacle. Journal of Thermal Analysis and Calorimetry, 135(2): 963-979. https://doi.org/10.1007/s10973-018-7349-x

[68] Tahari, M., Ghorbanian, A., Hatami, M., Jing, D. (2017). Physical effect of a variable magnetic field on the heat transfer of a nanofluid-based concentrating parabolic solar collector. Eur. Phys. J. Plus, 132(12): 549. https://doi.org/10.1140/epjp/i2017-11813-1

[69] Won, K.H., Lee, B.J. (2018). Effect of light scattering on the performance of a direct absorption solar collector. Front. $\quad$ Energy, 12(1): 169-177. https://doi.org/10.1007/s11708-018-0527-5

[70] Uddin, M.J., Alam, M.S., Rahman, M.M. (2017). Natural convective heat transfer flow of nanofluids inside a quarter-circular enclosure using nonhomogeneous dynamic model. Arab J. Sci. Eng., 42(5): 1883-1901. https://doi.org/10.1007/s13369-016-2330-0

[71] Nasrin, R., Parvin, S., Alim, M.A. (2015). Heat transfer and collector efficiency through a direct absorption solar collector with radiative heat flux effect. Numerical Heat Transfer, Part A, 68: 887-907. https://doi.org/10.1080/10407782.2015.1023122

[72] Pustovalov, V.K. (2018). Heating of single nanoparticles, their assemblies and ambient medium by solar radiation. Nanotechnology for Environmental Engineering, 3(1): 7. https://doi.org/10.1007/s41204-018-0036-0

[73] Rahman, M.M., Saha, S., Mojumder, S., Naim, A.G., Saidur, R., Ibrahim, T.A. (2015). Effect of sine-squared thermal boundary condition on augmentation of heat transfer in a triangular solar collector filled with different nanofluids. Numerical Heat Transfer, Part B, 68(1): 5374. https://doi.org/10.1080/10407790.2014.992058

[74] Zhang, S., Ge, Z., Wang, H., Wang, H. (2016). A new semi-analytical model for effective thermal conductivity of nanofluids. Physics and Chemistry of Liquids, 54(5): 647-662 https://doi.org/10.1080/00319104.2016.1139706

[75] Tullius, T.K., Bayazitoglu, Y. (2016). Analysis of a hybrid nanofluid exposed to radiation. Numerical Heat Transfer, Part B, 69(4): 271-286. https://doi.org/10.1080/10407790.2015.1104210

[76] Sheikh, N.A., Ali, F., Khan, I., Gohar, M., Saqib, M. (2017). On the applications of nanofluids to enhance the performance of solar collectors: A comparative analysis of Atangana-Baleanu and Caputo-Fabrizio fractional models. Eur. Phys. J. Plus, 132(12): 540. https://doi.org/10.1140/epjp/i2017-11809-9
[77] Pustovalov, V.K., Astafyeva, L.G. (2017). Spectral properties of nanofluids with homogeneous and bilayer nanoparticles for efficient absorption of solar radiation. Optics and Spectroscopy, 123(1): 158-163. https://doi.org/10.1134/S0030400X17070189

[78] Minea, A.A., Moldoveanu, M.G. (2017). Studies on $\mathrm{Al}_{2} \mathrm{O}_{3}, \mathrm{CuO}$, and $\mathrm{TiO}_{2}$ water-based nanofluids: $\mathrm{A}$ comparative approach in laminar and turbulent flow. Journal of Engineering Thermophysics, 26(2): 291-301. https://doi.org/10.1134/S1810232817020114

[79] Mercatelli, L., Sani, E., Zaccanti, G., Martelli, F., Ninni, P.D., Barison, S., Pagura, C., Agresti, F., Jafrancesco, D. (2011). Absorption and scattering properties of carbon nanohorn-based nanofluids for direct sunlight absorbers. Nanoscale Research Letters, 61(1): 282. https://doi.org/10.1186/1556-276X-6-282

[80] Kaya, H., Arslan, K. (2019). Numerical investigation of efficiency and economic analysis of an evacuated U-tube solar collector with different nanofluids. Heat and Mass Transfer, 55(3): 581-593. https://doi.org/10.1007/s00231-018-2442-Z

[81] Akhatov, J.S., Mirzaev, S.Z., Halimov, A.S., Telyaev, S.S., Juraev, E.T. (2017). Study of the possibilities of thermal performance enhancement of flat plate solar water collectors by using of nanofluids as heat transfer fluid. Applied Solar Energy, 53(3): 250-257. https://doi.org/10.3103/S0003701X17030033

[82] Sadripour, S., Chamkha, A.J. (20198). The effect of nanoparticle morphology on heat transfer and entropy generation of supported nanofluids in a heat sink solar collector. Thermal Science and Engineering Progress, 9: 266-280. https://doi.org/10.1016/j.tsep.2018.12.002

[83] Chamkha, A.J., Selimefendigil, F. (2018). Numerical analysis for thermal performance of a photovoltaic thermal solar collector with $\mathrm{SiO}_{2}$-water nanofluid. Appl. Sci., 8: 2223. https://doi.org/10.3390/app8112223

[84] Chamkha, A.J., Dogonchi, A.S., Ganji, D.D. (2018) Magnetohydrodynamic nanofluid natural convection in a cavity under thermal radiation and shape factor of nanoparticles impacts: A numerical study using CVFEM. $\begin{array}{lll}\text { Appl. } & \text { Sci., } & \text { 8(12): }\end{array}$ https://doi.org/10.3390/app8122396

[85] Razmmand, F., Mehdipour, R., Mostafa Mousavi, S. (2019). A numerical investigation on the effect of nanofluids on heat transfer of the solar parabolic trough collectors. Applied Thermal Engineering, 152: 624-633. https://doi.org/10.1016/j.applthermaleng.2019.02.118

[86] Chen, M., He, Y., Zhu, J., Wen, D. (2016). Investigating the collector efficiency of silver nanofluids based direct absorption solar collectors. Applied Energy, 181: 65-74.

[87] Balakin, B.V., Zhdaneev, O.V., Kosinska, A., Kutsenko, K.V. (2019). Direct absorption solar collector with magnetic nanofluid: CFD model and parametric analysis. Renewable $\quad$ Energy, 136: 23-32. https://doi.org/10.1016/j.renene.2018.12.095 